\title{
Ligantes asfálticos modificados: Uma análise bibliográfica
}

\author{
Modified asphalt binders: A bibliographic analysis \\ Aglutinantes asfálticos modificados: Un análisis bibliográfico
}

Recebido: 26/03/2021 | Revisado: 01/04/2021 | Aceito: 03/04/2021 | Publicado: 13/04/2021

\author{
Alex Gomes Pereira \\ ORCID: https://orcid.org/0000-0003-3563-4161 \\ Centro Universitário São Lucas, Brasil \\ E-mail: alexgp885@gmail.com \\ Rafael Luis da Silva \\ ORCID: https://orcid.org/0000-0002-9485-479X \\ Centro Universitário São Lucas, Brasil \\ E-mail: rafaeluismat@gmail.com \\ Cristiano da Silva Vieira \\ ORCID: https://orcid.org/0000-0002-1276-0336 \\ Centro Universitário São Lucas, Brasil \\ E-mail: cristiano.vieira@saolucas.edu.br
}

\begin{abstract}
Resumo
A aplicação de ligantes asfálticos modificados em pavimentos rodoviários vem crescendo de forma sólida nas últimas décadas. Esse fato justifica-se por motivos diversos como o advento do grande avanço das indústrias químicas, a consagração da utilização de materiais poliméricos em obras de reforços e diversas vantagens que surgem desses fatos como economia, segurança, durabilidade, dentre outros. Nessa temática, o presente trabalho tem por objetivo fazer uma revisão bibliográfica abordando as principais pesquisas sobre ligantes asfálticos modificados.
\end{abstract}

Palavras-chave: Ligantes asfálticos modificados; Pavimentos; Novos materiais.

\begin{abstract}
The application of modified asphalt binders on road pavements has grown steadily in recent decades. This fact is justified by several reasons such as the advent of the great advance of the chemical industries, the consecration of the use of polymeric materials in reinforcement works and several advantages that arise from these facts such as economy, safety, durability, among others. In this theme, the present work aims to carry out a bibliographic review addressing the main researches on modified asphalt binders.
\end{abstract}

Keywords: Modified asphalt binders; Floors; New materials.

\begin{abstract}
Resumen
La aplicación de aglutinantes asfálticos modificados en pavimentos de carreteras ha crecido de manera constante en las últimas décadas. Este hecho se justifica por varias razones como el advenimiento del gran avance de las industrias químicas, la consagración del uso de materiales poliméricos en trabajos de refuerzo y varias ventajas que se derivan de estos hechos como economía, seguridad, durabilidad, entre otras. En este tema, el presente trabajo tiene como objetivo realizar una revisión bibliográfica abordando las principales investigaciones sobre ligantes asfálticos modificados.
\end{abstract}

Palabras clave: Aglutinantes de asfalto modificado; Pisos; Nuevos materiales.

\section{Introdução}

O asfalto utilizado em revestimentos asfálticos é aglomerante orgânico, de coloração escura, derivado da destilação do petróleo, cujo componente predominante é o betume (cerca de 99,5\% em sua composição). O betume é uma substância aglutinante (adesivo termoviscoplástico) escura, impermeável à água e pouco reativo, que se liquefaz quando aquecido. Com relação a sua constituição, o asfalto é uma mistura química complexa composta principalmente por de hidrocarbonetos e heteroátomos (oxigênio, enxofre, nitrogênio e os metais vanádio, níquel, ferro, magnésio e cálcio) (Bernucci, et al., 2008).

No Brasil, os asfaltos que são aplicados em pavimentação asfáltica são denominados de cimentos asfálticos de petróleo (CAPs), também chamados de ligantes asfálticos (Bernucci, et al., 2008).

De acordo com Advanced Asphalt Technologies (AAT) em sua norma National Cooperative Highway Research 
Program (NCHRP) 673, os ligantes asfálticos correspondem a 5\% em massa das composições asfálticas, sendo os $95 \%$ restantes constituídos pelos agregados minerais. Em termos volumétricos, estas proporções representam aproximadamente $10 \%$ de ligantes, $85 \%$ de agregados e $5 \%$ de vazios.

Silva et al. (2018) relatam que durante muitos anos, o desempenho do ligante asfáltico convencional foi considerado aceitável. Contudo, com o aumento do tráfego e das variações climáticas, tornou-se necessário o uso de materiais modificadores para melhorar as propriedades das misturas asfálticas. A partir disso, o estudo e o desenvolvimento de novas tecnologias de materiais para pavimentação asfáltica tem aumentado bastante motivados pelos diversos problemas que os pavimentos rodoviários têm enfrentado (Santos, Rodrigues e Mendonça, 2018).

Considerando esta abordagem, em tempos mais recentes, diferentes trabalhos foram desenvolvidos em diversas partes do mundo (Polacco, et al., 2005; Tayfur, Ozen e Aksoy, 2007; Xiao, et al., 2014; Dondi, et al., 2016; Huang e Huang, 2016; Sun, et al., 2016; Kumar, et al., 2016; Chen, et al., 2018; Bindu, et al., 2020; Liang, et al., 2020; Xin, et al., 2020; Vamegh, Ameri e Chavoshian, 2020).

No Brasil, mais especificamente no Grupo Rodovias Verdes/Laboratório de Pavimentação da Universidade Federal de Santa Catarina; Laboratório de Polímeros e Inovação de Materiais da Universidade Federal do Ceará; Sistemas de Infraestrutura Sustentáveis da Universidade Federal do Rio Grande do Sul; e Pavimentos e Novos Materiais de Pavimentos e Novos Materiais, observa-se o desenvolvimento de diferentes trabalhos, como: Pamplona et al. (2012); Melo (2014), Marcon (2016), Melo e Trichês (2016), Melo e Trichês (2016), Carlesso (2017), Melo e Trichês (2017), Andrade et al. (2017); Melo, Trichês e Rosso, (2018), Silva et al. (2018) e Carlesso et al. (2019).

Deste modo, o presente trabalho surge com intuito de realizar uma revisão da literatura sobre a modificação do ligante asfáltico.

\section{Metodologia}

Para o presente trabalho foi realizado por meio de uma revisão bibliográfica com abordagem qualitativa, exploratória e descritiva. A coleta de dados se deu por meio de busca eletrônica, o qual foi realizado um levantamento na página do Portal de Periódicos Coordenação de Aperfeiçoamento de Pessoal de Nível Superior/Ministério da Educação (CAPES/MEC) e na base de dados Scientifc Eletronic Library Online (SciELO). Os critérios de inclusão definidos foram: trabalhos publicados em português e inglês; e, trabalhos publicados nos últimos quinze anos.

Foram excluídos todos e quaisquer trabalhos que não se encaixam no escopo da pesquisa, como: artigos que não especificaram qual material foi utilizado para modificação do ligante asfáltico, assim como os trabalhos que modificaram o ligante asfáltico.

Após a consulta nas bases eletrônicas de dados, foram identificados 87 trabalhos sobre o tema em questão, deste total, foram eliminados 37 trabalhos, após a análise de duplicata (proveniente de diferentes bases ou de diferentes combinações de palavras chave). Em seguida a esta filtragem, o próximo passo foi a análise pela relevância acadêmica, o qual 27 trabalhos foram excluídos, o que resultou em 10 trabalhos.

\section{Ligante Asfáltico Modificado}

Pamplona et al. (2012) avaliaram as propriedades de ligantes asfálticos modificados simultaneamente por nanoargilas (Cloisite 20A, vermiculita e montmorilonita) e por polímero eStireno-Butadieno-eStireno (SBS). Para preparação dos compósitos asfálticos foi empregado um misturador de alto cisalhamento Silverson, modelo L4R. As amostras foram mantidas sob agitação contínua por 2 horas, sob velocidade de 2.000 rpm e temperatura de $160^{\circ} \mathrm{C}$.

Ao fim do processo de modificação, as amostras (exceto o ligante modificado pela nanoargila Cloisite 20A) foram 
caracterizadas por meio dos ensaios de penetração, ponto de amolecimento, susceptibilidade térmica e viscosidade rotacional. Os autores verificaram que os ligantes modificados apresentaram redução da penetração, aumento do ponto de amolecimento e aumento da viscosidade frente ao ligante convencional.

Em relação às propriedades reológicas, Pamplona et al. (2012) observaram que todos os ligantes modificados mostraram maiores valores de módulo de cisalhamento dinâmico e menores valores de ângulo de fase quando comparados ao ligante convencional, o que significa uma maior resistência destes ligantes ao fenômeno de deformação permanente.

Já o estudo de Melo (2014), avaliou o desempenho reológico e mecânico de composições asfálticas modificadas com nanoargila (NA) e nanotubo de carbono (NTC). A NA comercial utilizada na pesquisa foi a Dellite 67G, fornecida pela Laviosa Chimica Mineraria. O NTC foi adquirido junto à Nanostructured \& Amorphous Materials, Inc. Nestes nanocompósitos asfálticos, foram estudadas a inclusão dos nanomateriais variando em $3 \%$ para NA e $2 \%$ para NTC em relação ao peso do ligante asfáltico de petróleo 50/70.

O procedimento de modificação do ligante convencional foi realizado em um misturador de alto cisalhamento, modelo L5M-A Silverson, com velocidade de 5.000rpm, em temperatura de $150^{\circ} \mathrm{C}$, durante um período de compatibilização de 1 hora e 40 minutos. Quanto à caracterização dos ligantes estudados, os autores verificaram a diminuição na penetração e o aumento no ponto de amolecimento com a adição de materiais nanométricos.

No que diz respeito aos ensaios que avaliaram a ação deletéria da água (Lottman modificado) e deformação permanente por meio do simulador francês Laboratoire Central des Ponts et Chausses (LCPC), o autor observou melhor comportamento das misturas asfálticas nanomodificadas quando comparadas com a mistura convencional. Para avaliação das características reológicas das amostras estudadas, Melo (2014) utilizou o aparelho Pneumatic 4 Point Bending Apparatus (4PB). As amostras foram submetidas à frequências de $0,1 \mathrm{~Hz}, 0,2 \mathrm{~Hz}, 0,5 \mathrm{~Hz}, 1 \mathrm{~Hz}, 2 \mathrm{~Hz}, 5 \mathrm{~Hz}, 10 \mathrm{~Hz}, 20 \mathrm{~Hz}$ e $0,1 \mathrm{~Hz}$, temperaturas de $0^{\circ} \mathrm{C}$ a $30^{\circ} \mathrm{C}$, com carregamento sinusoidal contínuo e amplitude de deformação de $50 \mu \mathrm{m} / \mathrm{m}$. Os testes reológicos mostraram que as misturas asfálticas com nanocompósitos apresentaram maiores valores de módulo complexo e menores valores de ângulo de fase.

Quanto aos resultados de resistência à fadiga, novamente as misturas nanomodificadadas mostraram-se superiores à mistura convencional. Por fim, o autor concluiu que, em geral, os resultados apontaram vantagens técnicas das formulações nanomodificadas frente ao concreto asfáltico convencional.

Dando continuidade à bem-sucedida pesquisa de nanomodificação dos ligantes asfáltico, iniciado por Melo em 2014, Marcon (2016) e Carlesso (2017) estudaram os parâmetros mecânicos e reológicos de concretos asfálticos modificados como novos materiais. Marcon (2016) estudou misturas asfálticas nanomodificadas por polímero SBS, borracha moída de pneu, NA e NTC. As características mecânicas e reológicas das amostras foram obtidas mediante aos experimentos de resistência à ação deletéria da água no ensaio de Lottman modificado, à deformação permanente, módulo complexo e resistência à fadiga no aparato quatro pontos.

Quanto aos resultados, as amostras nanomodificadas por polímero SBS e borracha moída de pneu mostraram desempenho superiores quanto ao dano por umidade induzida. Quanto aos resultados de resistência à ação deletéria da água, as composições asfálticas nanomodificadas por polímero SBS e borracha moída de pneu mostraram desempenho superiores quanto ao dano por umidade induzida. No estudo reológico, as misturas asfálticas modificadas por SBS e borracha moída de pneu apresentaram valores de módulo complexo e ângulo de fase inferiores aos valores encontrados para as misturas de nanomodificadas por nanoargila organofílica e nanotubo de carbono.

No mesmo contexto, Carlesso (2017) estudou as propriedades de ligantes asfálticos modificados simultaneamente por nanoargila e o polímero SBS. A modificação da matriz asfáltica por SBS foi conduzida em temperatura de $180^{\circ} \mathrm{C}$ e velocidade de cisalhamento 5.000rpm, durante um período de 180 minutos. 
Após a produção dos nanocompósitos, os compósitos asfálticos foram submetidos aos ensaios de ação deletéria da água (Lottman modificado), à deformação permanente, módulo complexo e resistência à fadiga no equipamento $4 \mathrm{~PB}$ e a simulações numéricas. Na avaliação do efeito da ação deletéria da água e deformação permanente, a mistura 3\% NA + 2\% SBS mostrou-se superior às demais. No estudo reológico, apresentou módulos complexos relativamente elevados e os menores valores de ângulo de fase.

Os resultados dos ensaios de resistência à fadiga indicaram o comportamento superior das amostras modificadas em comparação à mistura convencional. Contudo, com base nas simulações numéricas, evidenciou-se a viabilidade da mistura 3\% $\mathrm{NA}+2 \%$ SBS frente à mistura de referência. Após a realização dos ensaios, o autor constatou-se que a composição asfáltica modificada por nanoargila e SBS torna-se uma alternativa promissora como material aplicável em pavimentos rodoviários.

Andrade et al. (2017), investigaram o comportamento reológico de ligantes modificados com $4 \%$ de resina do tipo fenol-formaldeído, obtida a partir do cardanol. Para o processo de modificação, os autores utilizaram um agitador de cisalhamento IKA, modelo RW20, com velocidade de agitação de 1.600rpm durante um período de 1 hora e 30 minutos na temperatura de $160^{\circ} \mathrm{C} \pm 5^{\circ} \mathrm{C}$.

Em relação às propriedades físicas, Andrade et al. (2017) observaram que os ligantes modificados apresentaram diminuição do valor de penetração e aumento do valor de ponto de amolecimento e viscosidade quando comparado ao ligante convencional. Quanto à caracterização dos ligantes estudados, os autores verificaram a diminuição na penetração e o aumento no ponto de amolecimento com a adição de materiais nanométricos.

No estudo reológico, comparando-se com o ligante de referência, Andrade et al. (2017), assim como observado em outras pesquisas, verificaram o aumento do módulo de cisalhamento dinâmico e diminuição do ângulo de fase. Esses resultados foram justificados em virtude das características surfactantes do oligômero, proporcionando uma melhor uma afinidade entre as moléculas apolares do ligante, como também os asfaltenos, estabilizando o sistema coloidal. Além disso, moléculas polares tendem a contribuir para um aumento na rigidez. Ou seja, a resina polimérica possibilitou ao ligante asfáltico uma maior rigidez e elasticidade, melhorando, assim, o desempenho do ligante em relação à deformação permanente.

Portugal et al. (2017) estudaram a incorporação de 1\%, 2\% e 3\% de óleo de milho (novo e residual) em dois tipos de ligante asfálticos: ligante convencional 50/70 e asfaltos modificados por polímeros (AMP 55/75). As amostras asfálticas foram caracterizadas por meio dos ensaios de penetração, ponto de amolecimento, viscosidade rotacional, envelhecimento em estufa de filme fino rotativo (RTFOT), especificação do grau de desempenho, fluência e recuperação sob tensões múltiplas (MSCR) e varredura de frequência. Os ligantes modificados foram preparados por meio de um agitador mecânico de baixo cisalhamento Fisatom, modelo 722D, com velocidade de $406 \mathrm{rpm}$ e temperatura de $135^{\circ} \mathrm{C}$, durante um período de compatibilização de 20 minutos.

De modo geral, os resultados mostraram que a adição de $1 \%$ de óleo de soja e milho (novo e residual) mantém as características físicas e reológicas sem comprometer o desempenho do CAP 50/70 ou do AMP 55/75. Os autores também relataram que não foi observada diferença significativa na utilização de óleo novo ou residual.

Carvalho (2018) analisou o comportamento mecânico de misturas asfálticas modificadas por etileno acrilato de metila e metacrilato de glicidila (S74), terpolímero de alta densidade (SX500) e ácido polifosfórico (PPA116\%). Após o processo de modificação foram confeccionadas as misturas asfálticas com 1,8\%S74, 0,3\%SX500 associadas a teores variados de 0,15; 0,3 e 0,5\%PPA116\%. As características mecânicas foram analisadas por meio dos ensaios resistência à tração por compressão diametral (RTCD), módulo de resiliência (MR), módulo dinâmico (MD), flow number (FN), Lotman modificado e desgaste Cântabro. Como resultado, o autor verificou que as misturas asfálticas modificados com polímero reativo/não-reativo associados ao ácido polifosfórico nos teores de 0,3 e 0,5\%PPA116\% mostrou maior resistência à deformação permanente quando submetidos a altas temperaturas, maior resistência ao desgaste e menor susceptibilidade à umidade. 
No estudo de Santos, Rodrigues e Mendonça (2018) avaliaram as propriedades físicas e reológicas do ligante asfáltico modificado por lignina kraft proveniente da madeira de eucalipto. O procedimento de modificação consistiu na adição de 3\%, $6 \%$ e $9 \%$ de lignina em relação ao peso do ligante asfáltico 50/70. Os autores observaram que os ligantes modificados por lignina se mostraram mais resistentes à variação de temperatura, à deformação permanente e ao envelhecimento.

Silva et al. (2018) analisaram as propriedades de ligantes asfálticos modificados por PET. No estudo dos autores, o procedimento de modificação do ligante convencional em um misturador de asfalto Modelo 722D, com rotações de $2.000 \mathrm{rpm}$, sob temperatura de $165^{\circ} \mathrm{C}$ e por um período de tempo de mistura de 2 horas. Os autores concluíram que o ligante modificado apresentou comportamento superior ao ligante convencional em todos os ensaios realizados.

Recentemente, observa-se um crescente interesse no uso de óleos vegetais como modificador de ligante asfáltico. Esses materiais mostram muita versatilidade quanto à sua utilização, custo relativamente baixo e grande disponibilidade.

Luz et al. (2019) averiguaram as propriedades mecânicas de misturas asfálticas mornas modificadas com adição de óleos de milho e de soja (novo e residual). No estudo, os corpos de prova foram confeccionados em três temperaturas diferentes, no qual a primeira temperatura foi definida pelas curvas logarítmicas viscosidade $\mathrm{x}$ temperatura e as outras foram 10 e $20^{\circ} \mathrm{C}$ inferiores à primeira temperatura, respectivamente. Para avaliar o desempenho mecânico das misturas asfálticas, os autores conduziram os ensaios de RTCD, Lottman modificado, MR, FN e módulo dinâmico. De acordo com os resultados obtidos por Luz et al. (2019), a incorporação dos óleos vegetais na matriz asfáltica resultou na diminuição das comportamento mecânico e no desempenho reológico quando comparado ao ligante convencional.

\section{Conclusão}

O presente trabalho teve como objetivo realizar uma revisão da literatura sobre a modificação de ligantes asfálticos. Por meio deste levantamento foi possível verificar que o emprego do ligante asfáltico modificado por diferentes materiais vem demonstrando como uma alternativa promissora para a mitigação dos problemas relacionados à deterioração dos pavimentos rodoviários.

Deste modo, este trabalho abre portas para realização de futuros estudos abrangendo novos materiais para modificação do ligante asfáltico, buscando assim garantir o adequado desempenho dos componentes estruturais executados com este material e, consequentemente, mitigando a perda de funcionalidade e estrutural dos pavimentos rodoviários.

\section{Referências}

Bernucci, L. B., Motta, L. M. G., Ceratti, J. A. P., Soares, J. B. (2008). Pavimentação asfáltica: formação básica para engenheiros. PETROBRAS/ABEDA.

Bindu, C. S., Joseph, M. S., Sibinesh, P. S., George, S., Sivan, S. (2020). Performance evaluation of warm mix asphalt using natural rubber modified bitumen and cashew nut shell liquid. International Journal of Pavement Research and Technology, 13, 442-453.

Chen, C., Podolsky, J. H., Williams, R. C., Cochran, E. W. (2018). Laboratory investigation of using acrylated epoxidized soybean oil (AESO) for asphalt modification. Construction and Building Materials, 187, 267-279.

Dondi, G., Mazzotta, F., Simone, A., Vignali, V., Sangiorgi, C., Lantieri, C. (2016). Evaluation of different short term aging procedures with neat, warm and modified binders. Construction and Building Materials, 106, 282-289.

Huang, M., Huang, W. (2016). Laboratory investigation on fatigue performance of modified asphalt concretes considering healing. Construction and Building Materials, 113, 68-76

Kumar, K., Singh, A., Maity, S. K., Srivastava, M., Sahai, M., Singh, R. K., Garg, M. O. (2016). Rheological studies of performance grade bitumens prepared by blending elastomeric SBS (styrene butadiene styrene) co-polymer in base bitumens. Journal of Industrial and Engineering Chemistry, $44,112-117$.

Liang, R., Jin, R., Zhou, D., Sun, W., Kang, Y. (2016). Nonlinear rheological behaviors of epoxy asphalt binder compared to base asphalt binder and SBS modified asphalt binder at above ambient temperatures. Construction and Building Materials, 250, 118755.

Polacco, G., Berlincioni, S., biondi, D., Stastna, J., Zanzotto, L. (2005). Asphalt modification with different polyethylene-based polymers. European Polymer Journal, 41, 2831-2844. 
Research, Society and Development, v. 10, n. 4, e35710414321, 2021

(CC BY 4.0) | ISSN 2525-3409 | DOI: http://dx.doi.org/10.33448/rsd-v10i4.14321

Pamplona, T. F., Amoni, B. C., Alencar, A. E. V., Lima, A. P. D., Ricardo, N. M. P. S., Soares, J. B., Soares, S. A. (2012). Asphalt binders modified by SBS and SBS/nanoclays: effect on rheological properties. Journal of the Brazilian Chemical Society, 23 (4), 639-647.

Marcon, M. F. (2016). Estudo e comparação do desempenho mecânico e reológico entre concretos asfálticos modificados por polímero SBS, borracha moída de pneu e nanomateriais. Universidade Federal de Santa Catarina. Dissertação de Mestrado.

Melo, J. V. S. (2014). Desenvolvimento e estudo do comportamento reológico e desempenho mecânico de concretos asfálticos modificados com nanocompósitos. Universidade Federal de Santa Catarina, Tese de Doutorado.

Melo, J. V. S., Trichês, G. (2016). Caracterização da Resistência à Fadiga de Misturas Asfálticas Reforçadas Com Camadas Nanométricas de Silicatos. Revista Pavimentação, 42, 43-58.

Melo, J. V. S., Trichês, G. (2016). Effects of organophilic nanoclay on the rheological behavior and performance leading to permanent deformation of asphalt mixtures. Journal of Materials in Civil Engineering, 28 (11), 04016142.

Santos, N. S., Rodrigues, J. K. G., Mendonca, A. M. G. D. (2018). Efeito da adição de lignina kraft proveniente da madeira de eucalipto na reologia do CAP 50/70. Matéria, 23 (3), e12158.

Silva, J. A. A., Rodrigues, J. K. G., Carvalho, M. W., Lucena, L. C. F. L., Cavalcante, E. H. (2018). Avaliação reológica de ligante modificado com Politereftalato de etileno (PET). Matéria, 23, 11951.

Sun, Z., Yi, J., Huang, Y., Feng, D., Guo, C. (2016). Properties of asphalt binder modified by bio-oil derived from waste cooking oil. Construction and Building Materials, 102, 496-504.

Tayfur, S., Ozen, H., Aksoy, A. (2007). Investigation of rutting performance of asphalt mixtures containing polymer modifiers. Construction and Building Materials, $21328-337$.

Xiao, F., Amirkhanian, S., Wang, H., Hao, P. (2014). Rheological property investigations for polymer and polyphosphoric acid modified asphalt binders at high temperatures. Construction and Building Materials, 64, 316-323.

Xin, X., Liang, M., Yao, Z., Su, L., Zhang, J., Li, P., Sun, C., Jiang, H. (2020). Self-sensing behavior and mechanical properties of carbon nanotubes/epoxy resin composite for asphalt pavement strain monitoring. Construction and Building Materials, 257, $10,119404$.

Vamegh, M., Ameri, M., Naeni, S. F. C. (2020). Experimental investigation of effect of PP/SBR polymer blends on the moisture resistance and rutting performance of asphalt mixtures. Construction and building materials, 253, 119197. 